Int.J. Hum. Soc. Dev. Res.

ISSN (P):2521-1439; ISSN (E):2523-4331

Volume 2, № 2, 2018. 79-94

DOI: $10.30546 / 2523-4331.2018 .2 .2 .79$

\title{
Death Notices as Communicative Events: an Analysis of Linguistic Features in Jordanian Newspapers
}

\author{
Murad Hassan SA WALMEH \\ Dhofar University, Salalah, Oman
}

(C) The Author(s) 2018

\begin{abstract}
The present study is an attempt to conduct a genre analysis of Jordanian death notices. Drawing on the model of genre analysis proposed by Bhatia (1993), a sample of 100 Jordanian death notices has been randomly collected and examined to provide an overview of the main linguistic devices used in the texts and analyze to what extent such devices have a social purpose. The corpus analysis revealed that death notices go beyond announcing the death of a person to mirroring and deconstructing the social practices, values and beliefs of the Jordanian society that shape the construction of this genre. I hope that the results of this study will be of help in further raising cultural awareness.
\end{abstract}

C) 2018.All rights reserved

\section{ARTICLE HISTORY}

Received: 21/04/2018

Accepted: 18/08/2018

Published online: 05/10/2018

\section{KEYWORDS}

Generic structure, genre analysis, socio-cultural values, linguistic features, death notices 


\section{Introduction}

Death notices belong to a group of genres referred to by Miller (1984) as "homely discourse", which includes, as Al-Ali (2005) argues, announcement texts of everyday life such as birth, weddings, graduations, obituary announcements and the like. They have the specific function of telling a potential audience about the recent death of a person and contain other important details such as burial and funeral arrangements. Although there is limited and direct reference to death rituals within the death notice, the language used serves the same functions expressed through spoken rituals such as providing moral support, comfort and strength to the survivors (Sawalmeh, 2015).

Death notices in Jordanian newspapers written in Arabic are considered as communicative events. A communicative event is referred to as social events that serve some communication functions. It consists of "the discourse itself and its participants; namely, the producer and the receiver, the role of the discourse as well as the environment where the discourse is produced and received including its historical and cultural associations" (Swales, 1990).

In spite of their obvious prevalence and uniqueness, death notices have long been understudied homely genres in comparison with other types of genres. This research attempts to unravel some of the mysteries surrounding this popular widespread communicative event from which individuals can learn the practices and rules of specific social groups in a society. Ventola $(1987$, p. 6) argues that "learning foreign languages is learning how to behave linguistically in cultures other than one's own"; thus, this study will be useful for those people who are concerned with becoming familiar with and taking part in the social life of members from Jordanian culture. Moreover, this study serves as a useful resource about Jordanian society in terms of language use in a particular rhetorical context, as well as socio-cultural and religious background. In other words, this study is a window that provides a view into various aspects of Jordanian culture and a guide to the way through which Jordanian people construct and organize their death notices. The present paper seems to be an interesting enterprise, because while there is substantial body of research on the rhetorical structure of death notices (Eid, 2002; Al-Ali, 2005; Al-Khatib \& Salem, 2011; Sawalmeh, 2015; Aliakbari \& Tarlani-Aliabadi, 2015; Sawalmeh, 2018), it is difficult to think of a study in the existing literature devoted to the way that linguistic choices of a varying nature are related to the sociocultural and religious dimensions in death notices. With this in mind, the present study is organized as follows. After providing an overview of the previous research that has explored rhetorical generic moves rhetorical functions and linguistic features in the organization of this genre, I shall discuss the practicalities of how the data collection was conducted, and the model taken to data 
analysis. The fourth section will be dedicated to exploring the linguistic realizations of the rhetorical moves that characterize this genre, together with illustrative examples from the corpus. The conclusions obtained from the analysis will bring this study to an end.

\section{Theoretical background}

The present study draws on Bhatia (1993) genre analysis. The concept of genre has been discussed by several researchers from different fields such as literature, rhetoric, writing, linguistics, and anthropology. One of the most influential definitions of genre has been given by Bhatia (1993). He has proposed a comprehensive definition of genre:

It is a recognizable communicative event characterized by a set of communicative purpose(s) identified and mutually understood by the members of the professional or academic community in which it regularly occurs. Most often it is highly structured and conventionalized with constraints on allowable contributions in terms of their intent, positioning, form and functional value. These constraints, however, are often exploited by the expert members of the discourse community to achieve private intentions within the framework of socially recognized purpose(s) (P.49).

Accordingly, Bhatia (1993) conceives of genre analysis as a means to account for not only the way text is conventionally structured but also for the way it is interpreted, used and exploited in specific contexts to achieve certain goals. In the field of linguistics, genre analysis is used to describe the structure and stylistic features of texts (Coffin, 2001). What is of great significance in genre analysis is the proper identification of the communicative purposes of a text as well as the use of language within institutionalized settings controlled by communicative conventions created by a group of individuals in a defined discourse community (Bonyadi, 2012, p. 87). So, in this study, the analysis of death notice will focus on the main linguistic choices associated to the generic moves, and the socio-cultural explanations for the choices of structure and linguistic features.

In the past few years, two studies investigating the discourse of death notice have been carried out in Jordan (Al-Ali, 2005, Al-Khatib \& Salem, 2011). In a study which explored obituary announcements, Al-Ali (2005) used the Swalesian (1990) move analysis and studied the manifestations of solidarity and the promotion of pride which appear in obituary announcements in Jordanian society. In his move analysis, he surveyed his corpus consisting of 200 obituaries and assigned a set of common communicative functions according to various generic components within the obituary texts. As a result of this analysis, two different types (i.e., genres) of obituary announcements with significantly distinct textual functions were elucidated: one communicates a normal death and the other celebrates an unusual 
death, termed a 'martyr's wedding'. He found that the two different types of death announcements have nine recurrent component moves. Al-Ali (2005) concluded that although there were some similarities in generic component moves and communicative purpose of these two distinct, yet related, death announcements, the martyr's wedding' announcements differed from normal death announcements in that they promoted the deceased person and communicated a feeling of pride on the part of the obituaries.

In the same vein, Al-Khatib and Salem (2011) described the structural features and the euphemistic expressions related to death of obituary announcements in two different cultures: British and Jordanian. They provided some insights into the differences between British and Jordanian obituary announcements with detailed reference to the cultural background of the societies. The study data comprised three hundred death announcements evenly distributed by the two societies. The study showed that there were significant differences between obituary announcements in terms of their structure, function and language. These differences, they added, are mainly attributable to socio-cultural distinctions between the two societies. Unlike the studies conducted by Al-Ali (2005) and AlKhatib and Salem (2011), which mainly placed a great focus on structural patterns of Jordanian obituary announcements, the present study has gone some way towards enhancing our understanding of the generic textual patterns, the linguistic features and socio-cultural factors that shape the structure of this communicative event.

\section{Methodology}

\subsection{Corpus}

The death notices discussed in this study were randomly excerpted from the funeral sections of two popular and highly reputable daily newspapers in Jordan $A l-R a ' i$ and Al-Dustour, which henceforth will be referred to as AR and AD respectively. Death notices in other Jordanian newspapers were checked for comparison and it was observed that there are no significant differences in the pattern or style of these obituaries. The selection of AR and AD newspapers as sources for the obituary announcements was based on two criteria. First, they are regarded the most widely-used mediums to publish the largest number of classified obituary announcements in Jordan, whereas other dailies have only intermittent coverage. Second, both newspapers enjoy great prestige in Jordan, with daily circulation and geographical distribution, and thus have large readership based on this reputation. It is also worth noting that $\mathrm{AR}$ and $\mathrm{AD}$ are published in Arabic, the native tongue of the country. Therefore, the announcements published in the newspapers were transliterated and then translated into English in this study. In AR and $\mathrm{AD}$ newspapers, death notices were published in a separate section entitled "announcements", usually in the inner side of the newspapers, and were typically 
eight to seventeen lines long, primarily giving the name of the deceased person, and burial and funeral service arrangements.

To obtain the sample of death notices analyzed in this study, the chosen newspapers were selected over a period extending from 2012 to 2017. This period, I believe, is regarded long enough to reveal any variation in the death notices. Prior to choosing the sample, the researcher checked death notices in a number of issues of AR and AD newspapers. A preliminary textual analysis of a large number of death notices did not show significant differences in the generic structure of such announcements. Thus, a corpus of 100 death notices formed the basis of this investigation using simple random design, by which each obituary announcement had an equal probability of being included in the sample. Of the 100 death notices, 50 death notices were chosen from AR newspapers and 50 death notices were chosen from AD newspaper. Here, it is worth pointing out that the number of the newspaper death notices (100) which I collected randomly can be regarded large enough to enable us to pinpoint with a certain degree the reliability of the organizational schematic structures of the obituary announcements along with their linguistic characteristics.

\subsection{Procedures}

The theoretical assumptions on which the present paper relies are mainly derived from Bhatia's (1993) genre analysis approach. This socially and linguisticallyoriented approach goes beyond the language analysis of texts and relates the linguistic patterns and elements found in death notices to the social conventions of the death rituals. In other word, the strength of this approach lies in the fact that it goes far beyond the examination of patterns of text organization and lexicogrammatical description of language use in a given genre text (thin description) by incorporating the social context and the communicative purposes of the genre under study (thick description).

As far as the analysis of micro-linguistic features of the genre under study, it was divided up into meaningful units, essentially on the basis of linguistic clues, and then it was analysed for the purpose of investigating the salient lexico-grammatical choices and strategies which characterize each identified rhetorical move; that is, to look into their linguistic features from syntactic and rhetorical.

Arabic language is very rich in rhetorical and stylistic devices which are utilized to perform specific rhetoric functions in their context through invoking meaning that goes beyond the lexical meaning of words (El-dali, 2012; Abdullah et al., 2016). It is not surprising, therefore, to find out that the genre of death notices constitutes a fertile ground for the proliferation of such linguistic and literary devices (Fernandez, 2006; Bressler, 2009). The microlingusitc features examined in this study are considered the most common ones used in the genre of death notices. 
The choice of these linguistic features was not at random. Rather, certain moves of the genres, apart from their rhetorical functions, are characterized by specific distinct stylistic features associated with them.

\section{Results and discussion}

Before examining the linguistic features of the genre under study, it is of significance to initially present the generic structure (moves) of death notices genre.

The elements in a typical death notice appear in the following order: Opening, Heading (Obituary), Announcing the death, Identifying the deceased, Identifying surviving relatives, Identifying circumstances of death, Funeral arrangements, Arrangements for receiving condolences, Notifications, and Closing. This section traces and explores the micro-linguistic features of this genre with the intention of seeing how Jordanian obituarists organize their death notices. It focuses on the salient syntactic and rhetorical properties.

\subsection{Syntactic features}

This section presents the prevalent syntactic features in the death notices text such as sentence length, sentence complexity, verb tenses, nouns, adjectives, prepositions, ellipsis, etc.

\subsubsection{Sentence length}

Sentence length, in this study, is going to be determined by calculating the number of words for each move in the death notice corpus by hand, i.e., to find out how many words constitute each discoursal move in the death notice genre. The analysis of the data indicated that there is variation in sentence length across obituary announcements. Any differences in length of the death notice may be reflective of differences in the socioeconomic statuses of both the deceased and his or her family (Eid, 2002). The size of the death notice, in Jordan, is determined by its cost. That is, the bigger the obituary announcement is, the higher its cost is. death notices are usually made by the family, a friend, a relative, or a colleague of the departed person. The cost of a single death notice may range from $15 \mathrm{JD}$ (28\$) to $500 \mathrm{JD}$ (700\$), relying on the size and the place of announcement.

In the light of what was mentioned above, it can be argued that Jordanian obituarists, who belong to low social class, use short sentences when constructing their obituary announcement text and try to reduce the average sentence length to an acceptable length, perhaps due to the fact that they want to reduce the cost of such obituary announcements for economical reasons. In other words, they are trying to save space and money because words cost a lot of money in obituary announcements. However, Jordanian obituarists, who enjoy a higher socio- 
economic status and occupy important official positions or occupations, use long sentences and their obituary announcement usually occupies the whole page in the newspaper. The long obituary is a reflection of how much the family members of the deceased are willing to pay to make a more expressive public announcement (Barth, Van Hoof, \& Beldad, 2014). Therefore, it could be argued that the obituary length, which indicates the costs the family members of the deceased shoulder, might reveal the value attached to the dead person by the bereaved.

\subsubsection{Verb Tense}

The present section focuses on three verb tenses in the texts of obituary announcements, namely, the present tense, the past tense and the future tense. The main objective of the analysis is to find out the preferred verb tense used in each move of obituary announcements. In general, the analysis of the data revealed some substantial variations in the tense choice of verb tenses in the corpus.

The corpus analysis showed that the move of "Announcing the death" was marked with the predominant use of the present tense. In this move, although the death happened a day or two days before writing the obituary in the newspaper, the obituarist uses the present verb (ينعى yan a $_{\text {a) }}$ ) to announce the death of a person. The obituary writer's use of the present tense rather than the past tense could possibly be a clear indication that the loss of the loved person is still very painful, and the grief of the deceased person's family and relatives is still deep and great. The move of "Identifying circumstances of death" was realized by the use of the past tense only. The obituary writer's use of the past verbs such as (اسلمت (نتل) Pintaqal) and ?aslamat) indicates that the death of the person occurred in the past. The use of the past tense is obligatory in this move since the obituary was announced in the newspaper after the occurrence of death. The obituary writer cannot use the present or the future tenses to announce the person's death which occurred a day or two days before writing the obituary in the newspaper.

The "Funeral and burial arrangements" move, which performs an informative function, was realized by the use of the feature tense only. In this move, the future verb (وسيشع wasaufais) is used by the obituary writer to inform the reader that the body of the late deceased will be buried in his/her last abode at a specific time in the future. As far as the "Arrangements for receiving condolences" move is concerned, it was realized by the use of the present tense to express the future. The obituary writer uses the present verb (قبلُ thqbal) to inform the reader that the condolences will be received at a specific time in the future. As for the "Identifying the deceased" move and the "Identifying surviving relatives" move, they do not contain any present, past or future tenses at all. These moves were characterized by the use of proper nouns (i.e., the names of deceased people and surviving relatives). 


\subsubsection{Nouns}

A careful analysis of the data of the present study yielded the result that nouns in these death notices are abundant and plentiful. A close look at the the "Opening" move, the "Announcing the death" move and the "Closing" move shows that they are characterised by the use of proper and common nouns such as "Allah" (الله" Pal:h); "God" (ب rab); "soul" (نف nafs); "paradise" (الجنة Paldzannah); "Christ"

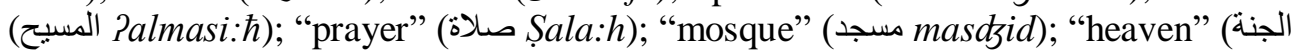
Paldzannah); "priest" (القسيس Palqisi:s); "Chursch" (الكنيسة Palkani:sah). The use of

such nouns reflects the religious background and the Muslim and Christian obituary announcer. The "Identifying the deceased" move and the "Identifying surviving relatives" move are featured by the extensive use of nouns many common nouns such as "doctor" ( الدكتور Palduktu:r); "teacher" (الاستاذ Pal?usta:ð); "engineer"

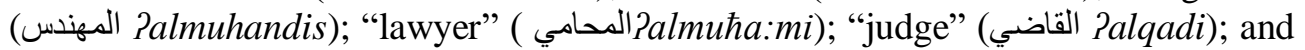
"pilot" (الطيار Paltaya:r). Using such nouns, which represent professional and academic titles, in the "Identifying the deceased" move indicates that the obituary announcer tries to acknowledge the deceased person in a positive way by showing his or her professional and academic attributes and glorifying his or her achievements. In the "Identifying surviving relatives" move, the families of the deceased person use these nouns to show their social status by mentioning the titles of some of their relatives and the positions they might hold in the society. This confirms the claims of Rajula (2008), Al-Ali (2005) and Afull (2012) that the obituary genre is a breeding ground for showing the socio-economic status of the deceased person and his or her family.

Moreover, the "Identifying surviving relatives" move is characterised by the

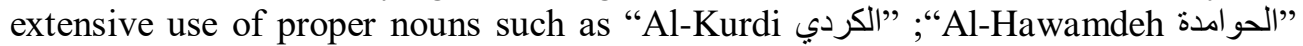

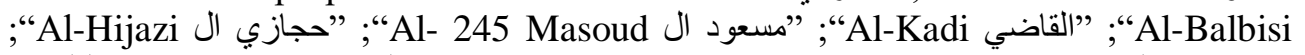
These proper nouns represent the names of the obituarist's families. They use the family name to reflect their solidarity, pride and belongingness to their tribes.

\subsubsection{Adjectives}

The results of the analysis showed that the distribution of the adjectives across the component moves showed that the adjectives are more frequently employed in the "Arrangements for receiving condolences".

A detailed analysis of the distribution of the adjectives across the component moves showed that the writers of obituary announcements tend to use key lexemes (adjectives) such as "forgiven" ( المرحوم (2almagfu:r); "the mercy-receiver" Palmarћu:m) in the "Heading" move and the "Announcing the death" move. 
This tendency might inspire a positive view of death and imply a positive view of earthly life which fuels forgiveness and mercy after death (Al-Kharabsheh, 2011, p. 37).

Also, the announcer uses many adjectives to give descriptions of the character of the deceased person. These descriptions revolve around the deceased person's positive traits. Giving some descriptions such as "virtuous" ( فاضل fa:dil); "caring" ( المربي Palmurabi); "loving" ( المحب Palmhib) could be seen as a strong desire to share personal details about the deceased person in public, and reveals how the Jordanian society respects and cherishes the deceased person and tends to feel great sense of loss when the person passes away. The use of positive adjectives are crucial when bringing a text to life and their implementation affords intimacy (Barth, Van Hoof \& Beldad, 2014), and could indicate closeness to the deceased (Halbur and Vandagriff, 1987). It should be pointed also that apart from soothing and alleviating the pain of death, such linguistic choices show the attitude of Jordanian people towards death- a sense of loss.

\subsubsection{Ellipsis}

Ellipsis is one of the prominent linguistic phenomena found in the Arabic language, in both written and spoken forms. Ellipsis can be defined as the omission of unnecessary words or phrases from a sentence. A careful examination of the death notice genre revealed that there are four types of ellipsis. These types include verbal ellipsis, nominal ellipsis, prepositional phrase ellipsis and vocative particle ellipsis.

Analysis of the data revealed that Jordanian obituarists who are of low social status highly prefer ellipsis when writing an obituary announcement in a newspaper. One of the main purposes of ellipsis, as Hassan and Taqi (2011, p. 645) put it, is to decrease the number of words in a text. Therefore, Jordanian obituarists tend to make their obituary announcements concise and brief and try to reduce the number of words by using ellipsis. This is probably due to the fact that they tend to spare more print space to save money, as the more words the obituary announcement contains, the more money it will cost. This view is supported by Al-Khatib and Salem (2011) who state that "the size of an obituary indicates the socioeconomic status of its writer who normally is one of the deceased's family or associates. This is because the bigger ones cost more". Consider the following examples below which employ the phenomenon of ellipsis whereby the elided material is indicated with brackets. 
naSi [radzul] fa:dil

نعي[رجل] فاضل

(Obituary announcement of a virtuous [man])

تُقبل التعازي للرجال و النساء في قاعة كنيسة مار افرام للسريان- [في حي] الصويفية ـ ولمدة ثلاثة أيام tuqbal altaGa:zi lilridza:l wannisa:? fi: qa:Sit kani:sat ma:r afra:m lilsara:ya:n [fi: hai ] PalȘweifiyyah - walimudat Oala:Oat Piyya:m

The condolences for men and women are received in the Mar Afram Lilsariyyan

Church - [in the district of] Al-Swaeifiyyah, for three days

\subsection{Rhetorical features}

\subsubsection{Alliteration}

Alliteration is another literary or figurative technique commonly used in the genre of death notices. It is defined as a figure of speech in which the same speech sound, especially initial consonants appears in two or more words that are next to or close to each other, as in this illustrative example: " The $\underline{\mathbf{b}}$ urghers of $\underline{B}$ righton $\underline{\mathbf{b}}$ riskly

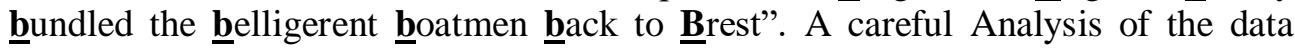
revealed that alliteration is widely used in the language of Jordanian obituary announcements. More specifically, this rhetorical figure /device has been explored in the structure of five constituent moves; namely, the "Opening" move, the "Identifying circumstances of death" move, the "Identifying the deceased" move, the "Funeral and burial arrangements" move and the "Arrangements for receiving condolences" move. However, the alliteration does not occur in the other moves of the obituary announcements. Consider the following examples from the corpus:

التي انتقلت إلى رحمة الله يوم أمس الثلاثاء عن عِر يناهز 89 عِاما اثر مرض عضال لم يمهلها طويلا

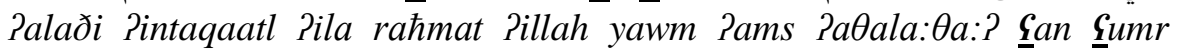

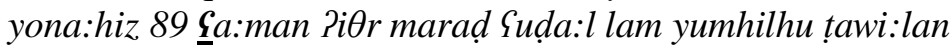

She who moved to the Almighty God's mercy on Tuesday yesterday, at the age of 89 , after suffering from a chronic disease

\subsubsection{Rhyme}

Rhyme is the repetition of the similar or identical sound or sounds of two or more words. Analysis of the data revealed that rhyme was used in the "Opening" move and "Announcing the death". Examples of this rhyme can be found in the following examples:

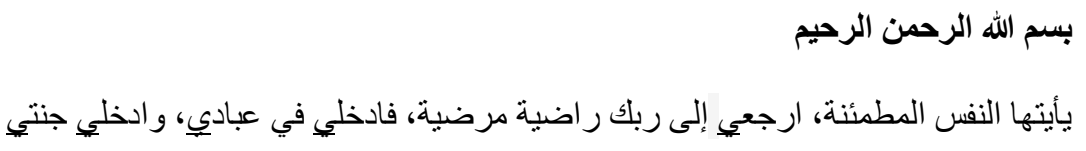

Int.J. Hum. Soc. Dev. Res.

Volume 2, № 2, 2018.79-94 
ya Payyatuha Pannafsu PalmuțaPinnah irdzifi_Pila: rabbiki ra:diyatun mardiyyah

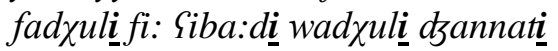

O the contented soul! Return towards your Lord - you being pleased with Him, and He pleased with you! Then enter the ranks of My chosen bondmen! And come into My Paradise

\subsubsection{Assonance}

Assonance is a repetition of vowel sounds within two words or more than two words to create rhythm. This rhetorical device occurred in one discoursal move of the obituary announcements, namely, the "Opening" move. In the example below, the underlined vowel sound/?/ is repeated four times in this move which stands for a quotation from the Holy Qur'an:

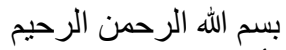

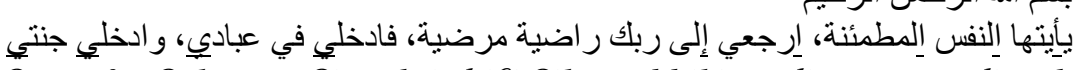

ya ?ayyatuha ?annafsu ?almutma

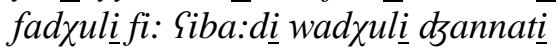

O the contented soul! Return towards your Lord - you being pleased with Him, and He pleased with you! Then enter the ranks of My chosen bondmen! And come into My Paradise

\subsubsection{Consonance}

Consonance is the repetition of a consonant sound two or more times in short succession. Typically, this repetition occurs at the end of the words, but may also be found in the middle or at the beginning of the words. A close examination of the genre of obituary announcements revealed that the rhetorical device, consonance was present in two different moves, viz., the "Opening" move, "Identifying circumstances of death" move and the "Funeral and burial arrangements" move. Consider the following illustrative examples from the data:

$$
\begin{aligned}
& \text { الذي أسلمت الروح إلى بارئها في الولايات المتحدة الأمريكيةـ كاليفورنيا- عن عِر يناهز } 78 \text { عامِا وذلك } \\
& \text { 2011/9/ }
\end{aligned}
$$

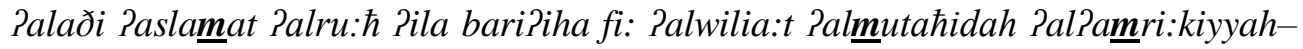

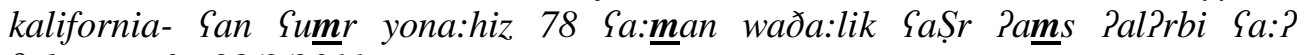
Palmuwa:fiq 28/9/2011 
He who moved to the Almighty God's mercy in the United States of America California- at the age of 78, on Wednesday yesterday 28/9/2011

\subsubsection{Parallelism}

Parallelism, also called parallel construction, is a salient feature of Arabic obituary announcement discourse. It can be defined as the similarity of syntactical structure in neighboring phrases, clauses, sentences or paragraphs, as in this illustrative example: "Let every nation know that we shall pay any price, bear any burden, meet any hardship, support any friend, oppose any foe to assure the survival and the success of liberty."

This device is widely noticed in the "Opening" move and "Closing" move, especially in the Qur'anic quotations, prophetic prayers or quotations from the Bible. Examples of parallelism in Arabic are exemplified by the following phrases taken from the death notices:

Parab asta warab Paxað

$$
\text { الرب أعطى و الرب أخذ }
$$

The Lord has given, and the Lord has taken away

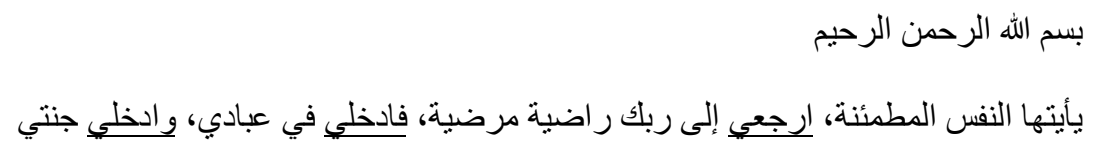

ya Payyatuha Pannafsu PalmuțaPinnah irdziSi Pila: rabbiki ra:ḍyatun mardiyyah fadzulifi:Siba:di wadzulidzannati

O the contented soul! Return towards your Lord - you being pleased with Him, and He pleased with you! Then enter the ranks of My chosen bondmen! And come into My Paradise

\subsubsection{Euphemism}

Euphemisms are words or expressions which can be used to avoid those expressions which are deemed to be taboo in a polite, indirect, tactful, mild and implicit way. In other words, they are used to soften or conceal unpleasant, hateful or embarrassing words and expressions. Euphemisms act as a veil, and they substitute these words and expressions with more delicate, pleasant, inoffensive and less shocking ones. 
Jordanian culture has always been in quest to search for methods to avoid or veil their referring to the idea of death directly. Euphemism is considered one of the methods adopted in such situations. As far as euphemizing death in Jordanian death notices is concerned, Jordanian culture employs a considerable majority of euphemistic death expressions in order not to make death sound so fearful. Moreover, it was noticed that death is handled with special care in Muslim and Christian obituary announcements texts to avoid bad omens as well as avoid hurting other people's feelings. Jordanian obituarists usually resort to euphemistic expressions to avoid the linguistic taboo words such as death and die with the objective of providing some sort of solace and consolation to those people left alive and help them accept the reality of the loss of a loved person. Consider the following two example:

التي انتقلت إلى رحمة الله يوم أمس الثلاثاء عن عمر يناهز 89 عاما اثر مرض عضال لم يمهلها طويلا

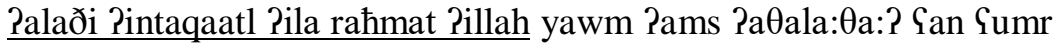
yona:hiz 89 Ga:man Pïr maraḍ Guḍa:l lam yumhilhu țawi:lan She who moved to the Almighty God's mercy on Tuesday yesterday, at the age of 89 , after suffering from a chronic disease.

In the above example, which stands for the "Identifying circumstances of death" move, it is very apparent that Muslim and Christian obituarists tend to be more euphemistic when talking about tabooed topics like death. Therefore, they resort to euphemize the term ( مات ma:t) "died", which implies a sort of frightfulness and horror, by using the euphemized expression "He moved to the Almighty God's mercy". Further, it is worth pointing out that the above example represents a figurative euphemism, where this euphemism implicates that the death isfor the good of the deceased person, as s/he will go to the heaven. It should be mentioned that "most Arabic death terms are fatalism-laden, hence they seek to establish theistic agency and subsequently mitigate the resulting shock and grief" (Farghal, 1995, p. 370).

\section{Conclusion}

Death notices are not limited to merely announcing the death of a person; rather, they mirror Jordanian people's ideas and judgments, depending on many factors such as economic standing, religious beliefs, cultural practices, customs, etc. They are characterized as ceremonial genre texts generally constrained by socioreligiously motivated practices and conventions.

More specifically, in the light of the present research, the analysis of the death notices has revealed interplay between social and linguistic choices which can be summarized in five main points. First, death notices primarily achieved a social purpose. In fact, the explicit reference to academic and professional titles, which are written in bold-face with different sizes of font, reinforces socio-cultural values 
and reflects that the deceased's family belong to high socio-economic statuses in the Jordanian society. Second, religion played a prominent role in Death notices. The linguistic lexical choices reflected in different communicative moves of the corpus display many features of the influences exercised by religious beliefs of the obituarist in the texts. Examples of the religious lexical choices and phrases used by the producer of the death notices are "Al-haj", "Paradise", "mosque", "Allah", "Most Gracious" and "Most Merciful", "church", "God", "Christ", and "Heaven". Finally, the obituarist employs a set of rhetorical devices which have made the death notice genre look very eye-catching and persuasive for readers. They aimed at not only informing the readers of the death but also expressing their ideology achieved through using these rhetorical devices.

I hope to have demonstrated how this genre text is structured and interpreted to serve the communicative purposes agreed upon by members of Jordanian community who constantly take part in this genre and very aware of their social conventions. It is also hoped that this study has offered a rich account of the generic linguistic features of the genre text in relation to religious and socio-cultural values and practices of Jordanian society.

This study aimed to make a significant contribution to the study of genre of Jordanian death notices with the objective to analyze the linguistic features and communicative purposes practiced in these this genre to determine specific conventionalized purposes which are associated with different socio-cultural, as well as ideological backgrounds that Jordanian people practice in constructing and interpreting this genre. What is more, this study drew on the importance of contextualized genre analysis and explained that style, culture and religion, as well as norms determine the overall structure and linguistic features of this genre. Thus, it is also hoped that this study will serve as a window through which nonJordanians can improve their knowledge of the nature of these genres and can learn the rules and practices of specific social groups in Jordanian society.

\section{Disclosure statement}

No potential conflict of interest was reported by the author.

\section{Contact Information}

E-mail: msawalmeh@yahoo.com 


\section{References and notes:}

Abdullah, M. (2016). Figure of speech. Retrieved March 10, 2016, fromhttp://www.britannica.com/art/figure-of-speech

Al-Ali, M. N. (2005). Communicating messages of solidarity, promotion and pride in death announcements genre in Jordanian newspapers. Discourse \& Society, 16(1), pp.5-31.

Aliakbari, M., \& Tarlani-Aliabadi, H. (2015). Communicating sociocultural norms and social and religious practices in Iranian death notices. Social Semiotics, pp.123.

Al-Khatib, M. A., \& Salem, Z. (2011). Obituary announcements in Jordanian and British newspapers: A cross-cultural overview. Acta Linguistica, 5(2), pp.80-96.

Barth, S., Van Hoof, J. J., \& Beldad, A. D. (2014). Reading between the lines: a comparison of 480 German and Dutch obituaries. OMEGA-Journal of Death and Dying, 68(2), pp.161-181.

Bhatia, V. K. (1993). Analyzing genre: Language use in professional settings. Routledge.

Bonyadi, A. (2012). Genre analysis of media texts. Procedia-Social and Behavioral Sciences, 66,pp. 86-96.

Bressler, J. (2009). England adds some flair to obituaries. Retrieved March 6, 2016, from http://www.obitresearch.com

Coffin, C. (2001). Theoretical approaches to written language. New York: Macquarie University Press.

Eid, M. (2002). The world of obituaries: Gender across cultures and over time. Wayne State University Press.

El-dali, H. M. (2012). Toward an understanding of the discourse of advertising: Review of research, with special reference to Egyptian media. Global Journal of HumanSocial Science Research, 12(4).

Farghal, M. (1995a). Euphemism in Arabic: A grice an interpretation. Anthropological Linguistics, pp.366-378.

Fernández, C. (2006). The language of death: Euphemism and conceptual metaphorization in Victorian obituaries. SKY Journal of Linguistics, 19, 101-130.Halbur, B., \& Vandagriff, M. (1987). Societal responses after death: A study of sex differences in newspaper death notices for Birmingham, Alabama, 19001985. Sex roles, 17(7-8), pp.421-436.

Hassan, H. F., \& Taqi, J (2011). Nominal Ellipsis in English \& Arabic and its Influence on the Translation of the Meanings of Some Selected Qurànic Verses. Journal of College Of Education For Women, 22(3), pp.637-658.

Iseni, A. (2011). Assessment, Testing and Correcting Studentsxs' Errors and Mistakes. Language Testing in Asia, 1(3),p. 60.

Martínez, I. J., Tembra, J. J. V., \& Fernández, E. E., \& Iseni, A. (2016). Comparing Languages Through the Process of Story Making. The Reception of Linguistic Structures from Teacher's Training Students in Spain. ANGLISTICUM. Journal of the Association for Anglo-American Studies, 2(2), pp.44-52.

Miller, C. (1984). Genre as social action. Quarterly journal of speech, 70(2), pp.151-167.

Sawalmeh, M. H. (2014). A Sociolinguistic Study of Muslim and Christian Wedding Invitation Genre in the Jordanian Society. Journal: Journal of Advances in Linguistics, 5(1). 
Sawalmeh, M. (2015). Ceremonial Arabic Writing: A Genre-Based Investigation of Wedding Invitation Cards and Obituary Announcements in Jordanian Society (Doctoral dissertation, University of Huddersfield).

Sawalmeh, M. (2018). Jordanian Wedding Invitation as a Genre: An Analysis of Rhetorical Structure and Linguistic Features. International Journal of Linguistics, Literature and Translation, 1 (1),pp. 106-127.

Swales, J. (1990).Genre analysis: English in academic and research settings. Cambridge University Press.

Valero, A. L., Fernández, E. E., Iseni, A., \& Clarkson, C. P. (2008). The Attitudes Teachers Should Keep Towards Correcting Their Student's Errors and Mistakes. Porta Linguarum: revista internacional de didáctica de las lenguas extranjeras, (10), pp.21-30.

Ventola, E. (1987). The structure of social interaction: A systemic approach to the semiotics of service encounters. Pinter Pub Ltd. 